\title{
Animal rabies epidemiology in Nepal from 2005 to 2017
}

\author{
Pushkar Pal ${ }^{1,2}$ (D) Adisorn Yawongsa ${ }^{1}$, Rajesh Bhatta2 ${ }^{(\mathbb{D})}$, Hiroshi Shimoda ${ }^{(D)}$ and Theera Rukkwamsuk ${ }^{1}(\mathbb{D})$
}

1. Department of Large Animal and Wildlife Clinical Sciences, Faculty of Veterinary Medicine, Kasetsart University, Kamphaeng Saen, Nakhon Pathom 73140, Thailand; 2. Department of Veterinary Pathology and Clinics, Agriculture and Forestry University, Nepal; 3. Laboratory of Veterinary Microbiology, Joint Faculty of Veterinary Medicine, Yamaguchi University, Yamaguchi 753-8515, Japan.

Corresponding author: Theera Rukkwamsuk, e-mail: fvettrr@ku.ac.th

Co-authors: PP: ppal@afu.edu.np, AY: fvetady@ku.ac.th, RB: rbhatta@afu.edu.np, HS: hshimoda@yamaguchi-u.ac.jp Received: 19-04-2021, Accepted: 20-08-2021, Published online: 13-10-2021

doi: www.doi.org/10.14202/IJOH.2021.190-195 How to cite this article: Pal P, Yawongsa A, Bhatta R, Shimoda $H$, Rukkwamsuk T (2021) Animal rabies epidemiology in Nepal from 2005 to 2017, Int. J. One Health, 7(2): $190-195$.

\begin{abstract}
Background and Aim: Animal rabies is endemic in Nepal, and it occurs in two forms. Although governmental and non-governmental agencies are working toward the control of rabies by mass dog vaccination and stray dog population management, there is still massive number of rabies incidence reported to the reference veterinary laboratory, Nepal. Therefore, this study aimed to assess animal species, temporal, regional, and agro-ecological distribution patterns of animal rabies in Nepal from 2005 to 2017.
\end{abstract}

Materials and Methods: The epidemiological data on animal rabies from the period of 2005 to 2017 were obtained from the Central Veterinary Laboratory, Tripureshwor, Kathmandu, Nepal. The laboratory-confirmed rabies cases were analyzed according to animal species, temporal, regional (developmental zones), and agro-ecological distributions. In addition, descriptive statistics were used to evaluate the distribution patterns of rabies.

Results: From 2005 to 2017, a total of 2771 suspected rabies cases in animals were reported to The Central Veterinary Hospital, Kathmandu. Of which, 1302 were found laboratory-confirmed cases. The rabies cases were most commonly reported and confirmed in dogs followed by other domestic animals. The high occurrences were recorded between 2005 and 2007. However, the incidence was increased during 2016 and 2017. The highest number of rabies cases was recorded in the eastern development zone, and the least number in the central zone at regional level. Likewise, it was highest in the Terai (plain) region and lowest in mountainous areas at agro-ecological zones. The findings also revealed that the occurrences of rabies significantly differed among seasons.

Conclusion: Rabies is present in Nepal throughout the year and all seasons with seasonal variation. Among the animal species, dogs are the primary animals affected with rabies followed by cattle and other domestic animals. At the regional level, eastern development zone had the highest incidence and Central development zone recorded the least. Similarly, the Terai region had the highest incidence rates, and the least overall prevalence rate was observed in mountainous regions among agro-ecological zones. Therefore, the government should implement the strict enforcement of mass dog vaccination and dog population management through one health approach to control rabies incidence in the country.

Keywords: agro-ecological zones, animals, epidemiology, Nepal, rabies.

\section{Introduction}

Rabies is one of the ancient diseases of major public health problems. It is a neglected disease affecting human and livestock, and causes significant economic losses and important zoonoses [1]. A negative-stranded RNA virus causes the disease within Lyssavirus genus of the Rhabdoviridae family [2]. The bite of rabid animals most likely transmits the virus through saliva rich in the virus [1]. Rabies epidemiology, pathogenesis, public health concerns, and advances in diagnosis and control have been comprehensively reviewed [2]. However, the disease is always lethal once clinical symptoms have developed in both animals and human

Copyright: Pal, et al. This article is an open access article distributed under the terms of the Creative Commons Attribution 4.0 International License (http://creativecommons.org/licenses/ by/4.0/), which permits unrestricted use, distribution, and reproduction in any medium, provided you give appropriate credit to the original author(s) and the source, provide a link to the Creative Commons license, and indicate if changes were made. The Creative Commons Public Domain Dedication waiver (http:// creativecommons.org/ publicdomain/zero/1.0/) applies to the data made available in this article, unless otherwise stated. beings. Although the condition is effectively preventable through both pre-exposure and post-exposure vaccination, it still causes significant mortality of livestock and human in most developing countries [3]. The World Health Organization reports around 55,000 human deaths caused by rabies every year globally, out of which more than 35,000 deaths have been estimated to occur in Asian region. Bites from infected dogs are the main source of animal and human rabies in Asian continent, causing up to $95 \%$ of cases $[4,5]$.

In Nepal, rabies occurs in two cycles. The urban cycle rabies is primarily transmitted with the dogs and sylvatic rabies may be due to spillover infection between wild and domestic animal interaction [6]. Nepal estimated on an average 100 human deaths around the year [7]. The same number has been recorded for livestock deaths caused by rabies [8]. The majority of the rabies cases in both animals and human have been reported from Terai region than other two hilly and mountainous regions because of the higher population of human and animals in this region [6]. 
Frequent outbreaks of rabies occur in Nepal, affecting typically domestic animals such as cattle and goats through stray rabid dogs [9]. Although there are no official statistics on the dog population in Nepal, unpublished sources suggest that stray dogs in urban areas such as Kathmandu, Pokhara, Biratnagar, and Nepalganj were the primary source of rabies. Out of six lineages of rabies virus, Arctic lineage has been reported in canines [8]. Canine-mediated rabies accounts for $99 \%$ of transmission in both animal and human population in Nepal [10].

Animal rabies was an endemic and notifiable disease in 1995 in the country. However, human rabies is still not a notifiable disease in Nepal. Despite the attempts of stray dog population management and mass dog vaccination initiated by the department of livestock and animal welfare organization, still, there is a significant outbreak of rabies affecting domestic animals, probably due to a lack of coordinated approach in the government and non-governmental agencies working on rabies control programs [6]. According to animal species and areas affected through their periodicals, the Central Veterinary Laboratory (CVL) and Veterinary Epidemiology Centre annually publish the total outbreaks; confirmed cases and general distribution of rabies. In addition, few other independent epidemiological studies were also performed in the past $[7,11]$. The local journals such as Nepalese Veterinary Journal became online after 2017 and had documented the few cases and small-scale epidemiologic reports on animal and human rabies. The registered data also evaluated public awareness and molecular epidemiology of rabies in humans and dogs in Nepal [10].

This study aimed to compile the data from 2005 to 2017 to assess and evaluate the patterns of rabies distribution according to animal species, agro-ecological, regional, and temporal patterns of animal rabies distribution in Nepal using the data obtained from CVL, Kathamandu, Nepal, a reference veterinary laboratory. The findings are expected to assist the attempts of government and non -government agencies of Nepal working on rabies elimination programs in the country.

\section{Materials and Methods}

\section{Ethical approval}

The ethical approval was not necessary for this study; however, the source of data had been fully acknowledged.

\section{Data source and management}

The data for this study were obtained from Central Veterinary Hospital, Tripureshwor, Kathmandu, the government of Nepal, from mid-July 2005 to midJune 2017. Firstly, all confirmed rabies cases were compiled and categorized according to (1) animal species-wise outbreak (2) monthly prevalence, (3) yearly prevalence, and (4) seasonal prevalence to observe the temporal distribution of rabies in Nepal. We further categorized the same data into eastern, central, western, mid-western, and far western developmental zones to know the rabies prevalence at regional level (Figure-1). Likewise, the dataset was also analyzed according to three agro-ecological regions, such as mountains, hills, and Terai (plain) regions (Figure-2), to illustrate the distribution pattern of animal rabies occurrence in these areas.

\section{Statistical analysis}

Descriptive analysis was performed to describe the frequencies of the disease. The 13 years data were aggregated into monthly and yearly number of cases and the time series plots were created to visualize potential trends and seasonality. By adding the frequencies of rabies incidence across Nepal's six seasons, the seasonal distribution was calculated: (1) summer (May to June), rainy (July to August), autumn (September to October), pre-winter (November to December), winter (January to February), and spring (March to April). The expected numbers of cases were calculated under a null hypothesis that rabies occurrence was equally distributed among seasons in Nepal. Observed and expected numbers were analyzed by the Chi-square goodness-of-fit test to evaluate the rabies occurrence among seasons. In addition, descriptive analysis was used to describe the distribution of rabies in all five developmental zones and three agro-ecological zones. The frequency of rabies was summed up by the year to examine the annual trend in these locations.

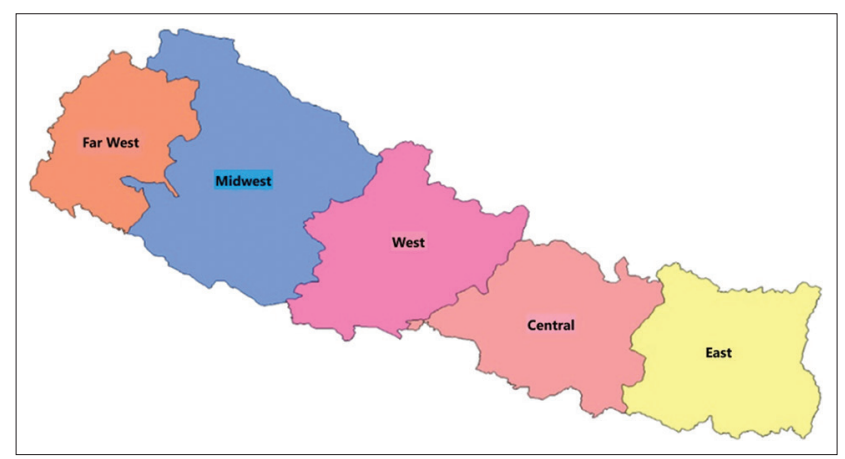

Figure-1: Five regions (developmental zones) of Nepal [Source: https://en.wikipedia.org/wiki/ Development_regions_of_Nepal].

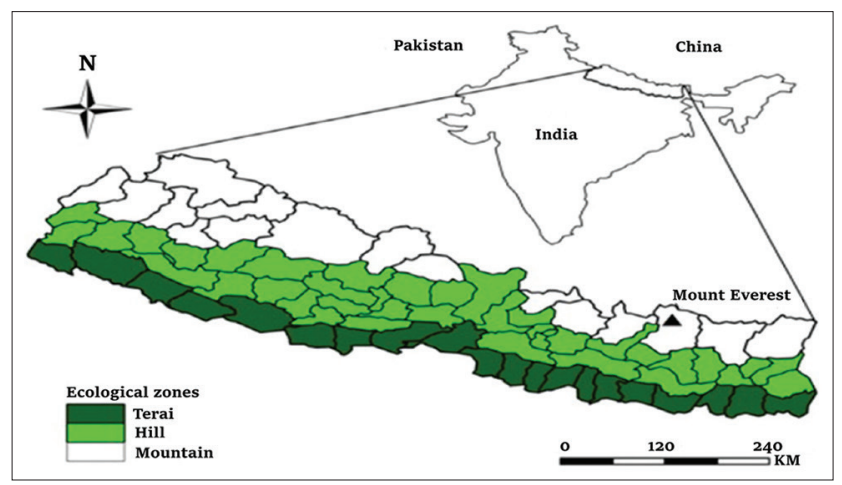

Figure-2: Three agro-ecological zones of Nepal [Source: Local Initiatives for Biodiversity, Research, and Development (LI-BIRD)]. 


\section{Results}

Prevalence of rabies in different categories (Animal species, Regional, and Agro-ecological zones)

From mid-July 2005 to mid-June 2017, a total of 2771 suspected rabies cases in different animal species were reported to Central Veterinary Hospital, Kathmandu, from various regions of Nepal. Of 2771 suspected cases, 1302 were laboratory-confirmed cases for the study period. The highest prevalence of rabies found in dogs $(37.10 \%)$, followed by cattle (23.19), buffalo (15.21\%), goat (10.98\%), sheep $(7.91 \%)$, pig $(3.30 \%)$, horse $(2.15 \%)$, and other species of animals such as yak $(0.08 \%)$ and monkey $(0.08 \%)$ (Table-1). Similarly, at a regional level, the eastern developmental zone recorded the highest prevalence rate $(26.34 \%)$ and central zone recorded lowest occurrence $(15.82 \%)$, whereas other three zones had in between cases ranging from 17.66\%-21.35\% (Table-2 and Figure-3). Accordingly, in agro-ecological category, findings showed that the rabies incidence was highest in Terai (plain) region followed by hills and mountainous regions (Table-3).

\section{Temporal pattern}

Rabies cases in Nepal occurred throughout the year. There was a high incidence in January and February followed by June, July, and August, and relatively low events were observed in rest of the months (Figure-4). The annual trend showed inconsistencies in the rabies distribution cases. The high prevalence

Table-1: Total number of confirmed animal rabies cases from 2005 to 2017 reported to the CVL, Tripureshwor, Kathmandu.

\begin{tabular}{lcc}
\hline Animal species & Confirmed cases & Percentage \\
\hline Dog & 483 & 37.10 \\
Cattle & 302 & 23.19 \\
Buffalo & 198 & 15.21 \\
Goat & 143 & 10.98 \\
Sheep & 103 & 7.91 \\
Pig & 43 & 3.30 \\
Horse & 28 & 2.15 \\
Yak & 1 & 0.08 \\
Monkey & 1 & 0.08 \\
Total & 1302 & 100.00 \\
\hline
\end{tabular}

Source: Central Veterinary Hospital, Tripureshwor, Kathmandu, Nepal. CVL=Central veterinary Laboratory

Table-2: Total number of suspected and laboratory-confirmed rabies cases in different developmental zones of Nepal from 2005 to 2017.

\begin{tabular}{lccc}
\hline Zone & $\begin{array}{c}\text { Number of } \\
\text { suspected } \\
\text { cases }\end{array}$ & $\begin{array}{c}\text { Number of } \\
\text { confirmed } \\
\text { cases }\end{array}$ & $\begin{array}{c}\text { Percentage } \\
\text { of confirmed } \\
\text { cases }\end{array}$ \\
\hline Eastern & 721 & 343 & 26.34 \\
Central & 535 & 206 & 15.82 \\
Western & 581 & 230 & 17.66 \\
Mid-western & 559 & 278 & 21.35 \\
Far-western & 375 & 245 & 18.81 \\
Total & 2771 & 1302 & 100.00 \\
\hline
\end{tabular}

Source: Central Veterinary Laboratory, Tripureshwor, Kathmandu, Nepal recorded between 2005 and 2007, and the cases were declined in a steady trend with an inconsequential variation until 2013. However, the number of cases increased from 2014 to 2017 with a slight drop in 2015 (Figure-5).

Regarding seasonal distribution, the cases were highest in the winter, followed by rainy season, summer, autumn, spring, and pre-winter (Table-4). Thus, the data revealed that the prevalence of rabies significantly differed among seasons.

\section{Discussion}

Distribution of rabies cases in different categories (Animal species, Regional, and Agro-ecological)

In the category of animal species-wise occurrence, we found the highest number of rabies prevalence in dogs. This could be because of the large number of stray dogs in the country. The unpublished report by Kathmandu Animal Treatment Center in 2012, showed 22500 stray dogs in Kathmandu, the capital city of Nepal. Besides, most dog owners leave their dogs on the street whenever their dogs get sick. This is due to an unaffordable medical cost likely to incur for the treatment of sick dogs. This caused increased aggression between dogs competing for limited resources that, in turn, increased the opportunity for rabies transmission [12]. The cattle population

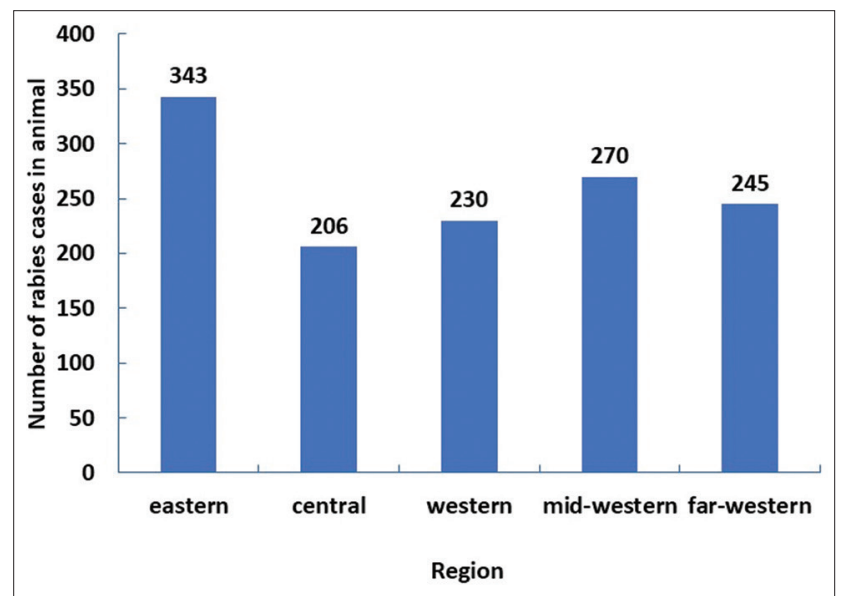

Figure-3: Rabies occurrence in the five regions of Nepal from 2005 to 2017.

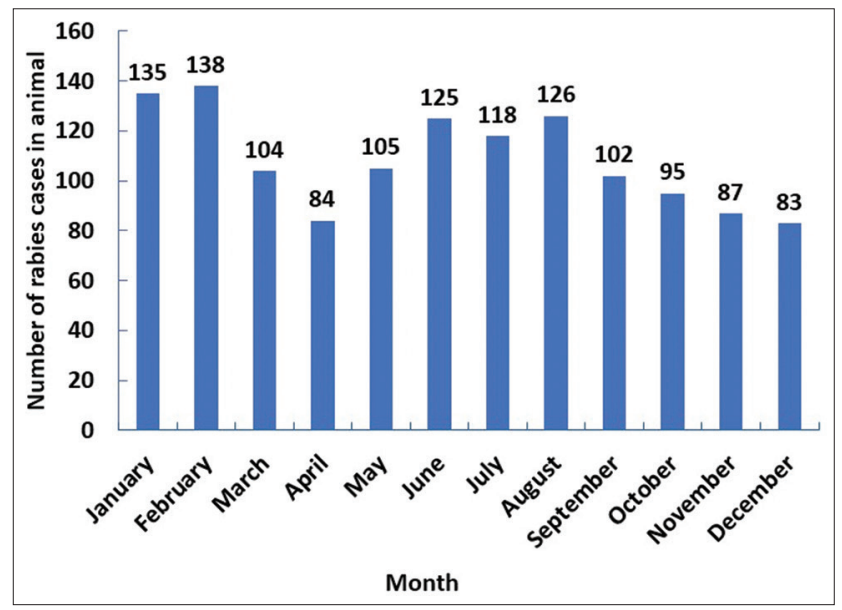

Figure-4: Monthly distribution of laboratory confirmed rabies cases in animals in Nepal from 2005 to 2017. 
Available at www.onehealthjournal.org/Vol.7/No.2/6.pdf

Table-3: The occurrence of the rabies in three agro-ecological regions from 2005 to 2017.

\begin{tabular}{|c|c|c|c|c|c|c|c|c|c|c|c|c|c|c|}
\hline Eco-zone & 2005 & 2006 & 2007 & 2008 & 2009 & 2010 & 2011 & 2012 & 2013 & 2014 & 2015 & 2016 & 2017 & Total \\
\hline Mountain & 7 & 0 & 0 & 0 & 0 & 0 & 0 & 0 & 3 & 22 & 5 & 15 & 8 & 60 \\
\hline Hill & 21 & 68 & 93 & 14 & 6 & 31 & 17 & 11 & 24 & 112 & 12 & 71 & 132 & 612 \\
\hline Terai & 102 & 56 & 36 & 45 & 29 & 31 & 35 & 42 & 36 & 36 & 52 & 63 & 76 & 630 \\
\hline Total & 130 & 115 & 129 & 59 & 35 & 62 & 52 & 53 & 63 & 170 & 69 & 149 & 216 & 1302 \\
\hline
\end{tabular}

Source: Central Veterinary Laboratory, Tripureshwor, Kathmandu, Nepal

Table-4: Seasonal distribution of laboratory-confirmed rabies cases in animals in Nepal from 2005 to 2017.

\begin{tabular}{lc}
\hline Season (Month) & Observed cases \\
\hline Winter (January-February) & 273 \\
Spring (March-April) & 188 \\
Summer (May-June) & 230 \\
Rainy (July-August) & 244 \\
Autumn (September-October) & 197 \\
Pre winter (November-December) & 170 \\
Total & 1302 \\
\hline
\end{tabular}

$* \chi^{2}=34.49, \mathrm{df}=5, \mathrm{P}<0.05$

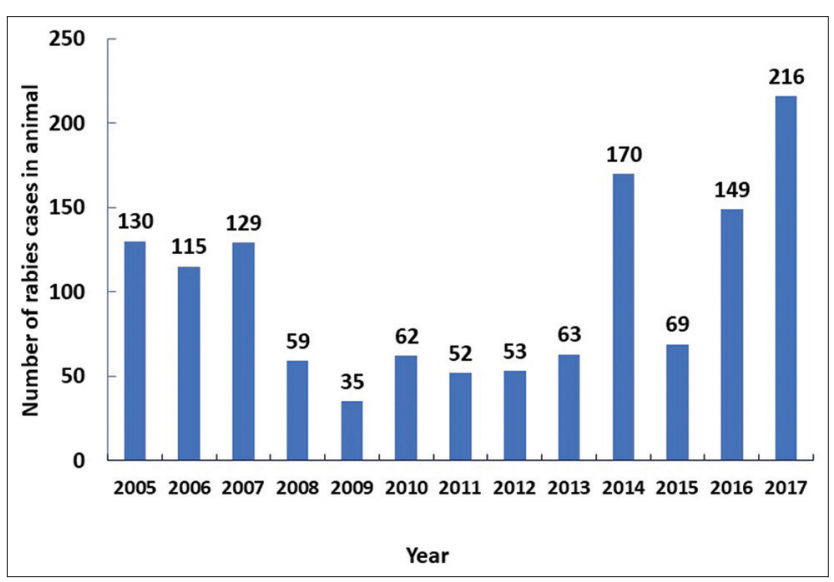

Figure-5: Annual trend of laboratory-confirmed rabies cases in animals in Nepal from 2005 to 2017.

was found to be at risk next to dog population. This species of animals could have caught the disease from rabid stray dogs. In Nepal, the cattle, buffalo, goat, and sheep are grazed on open fields and there are high chances of getting contact with free-roaming dogs. This finding is in agreement with the study done in Bhutan and elsewhere in the world [12-14].

The regional (developmental zones) pattern of rabies occurrence demonstrated the highest incidence of confirmed rabies cases in the eastern developmental zone. This might be due to its close proximity and accessibility to CVL, a veterinary referral hospital for rabies diagnosis. Furthermore, this is the region with higher number of domestic animals. The lowest incidence rate was observed in the central developmental zone. The low occurrence might be due to increased awareness level about rabies in the community and availability of rabies vaccines along with dog sterilization programs in urban areas $[15,16]$. The rest three developmental zones had a medium range of rabies occurrence. Analysis for agro-ecological zones revealed that the highest incidence was found in the
Terai region. India, having the largest stray dog population freely borders this region, and there is a restriction-free movement of animals and humans almost across the borderline. Due to free-ranging pasture lands available in this area, livestock is more vulnerable to rabies transmitted by dogs. In addition, this region possesses the urban area's dense population of humans and animals. This is similar to the study that the dogs are the reservoir and vector of rabies virus transmission to other livestock species in canine rabies endemic countries $[13,17]$. According to the authorities, no wildlife rabies cases including rodents have been confirmed in Nepal. However, there are few confirmed cases in mongoose, elephants, jackals and foxes; a limited number of cases in elephants, might be due to spillover infections [18].

The incidence of rabies in the hilly region was also significantly higher than in the mountainous region and slightly less than that of Terai region. The region was spread over $65 \%$ of the total landmass and accommodated nearly half of the human population. We suspected that there were high chances of interaction between the livestock (cattle/sheep/goat) and the wildlife animals because of the grazing practices. There were frequent newspaper and personal reports that wild foxes and jackals, among other wildlife species, frequently invade the community in this region and spill over rabies infection might have caught the livestock. Similar findings have been reported from India [19] and Namibia [20].

The mountainous (Himalayan) region covers $15-16 \%$ of the total landscape. It is the least populated area due to the cold weather and very less fertile land. However, yak, sheep, and some species of goats that are tolerant to cold climate are reared in this region. The data revealed that there were only seven cases of rabies recorded during 2005 and the infection was disappeared until 2012 and there was re-emergence of infection consistently from 2013 to 2017 . The re-emergence of the disease was alarming for the community and animals in this region. In general, mountainous people with their animals migrate to temperate (hilly/plain) regions during the severe cold climates in the mountains. They spent several weeks to months in the hilly jungles during migration. During their stay in the jungles, animals might have caught rabies either from rabid dogs or spill over infection. This is in agreement with the study performed in Tanzania [21] and Eastern United States [22].

\section{Temporal pattern}

Rabies cases in Nepal occurred throughout the year. There was a high incidence in January 
and February followed by June, July, and August, and lower occurrences were observed in rest of the months. The higher incidence during winter and summer seasons might be associated with the breeding season of dogs. Several reports describe the rabies occurrence associated with the dog's breeding season [23-25] and wildlife animals [26]. The natural breeding of dogs increases the chances of physical contact leading to fighting among dogs increases the chances of virus transmission $[18,21]$. The incidence was higher in spring season than in other seasons of the year. The findings were similar to that of the study carried out elsewhere in Oman [12]. Although different regions have different temporal patterns of the rabies outbreak, several published reports confirmed the notion that there is a temporal effect on the occurrences of rabies outbreaks $[18,25,26]$. In addition, the understanding of demographic composition of free-roaming dogs is crucial for implementing effective interventions against rabies [27,28]. However, there is no comprehensive dog population census available in Nepal. The general assumption is that $10 \%$ of the human population is considered as the dog population in any particular area, so that the higher stray canine population might be the cause of the presence of rabies throughout all the seasons. This finding agrees with the study carried out in South Africa and elsewhere [14,29,30].

We found that rabies was present in Nepal throughout the year. The annual incidence trend showed above 100 rabies cases during 2005-2007. The increased cases during this period might be attributed to absence of the programs for mass vaccination and stray dog population management [28,31,32]. After 2008, few animal welfare organization (NGOs) such as Kathmandu Animal Treatment Centre in 2008 and Animal Nepal, in Kathmandu focused on stray dog population management along with rabies vaccination, thereby contributing towards rabies reduction in Kathmandu, Nepal. As most of the rabies cases were reported from Kathmandu (urban) area, the decreased occurrence from 2008 to 2013 could be due to combined efforts of mass rabies vaccination conducted by the Department of Livestock Services and NGOs. In recent years, Department of Livestock Services and NGOs vaccinate stray dogs on the occasion of "rabies day" every year. In addition rabies vaccine production laboratory of Nepal produces 40,000 dosages per annum and OIE donated 20,000 rabies vaccines which could have played a significant role in the reduction of rabies cases during this period. However, there was an abrupt rise in the number of rabies cases from 2014 and reached to peak in 2017. This increased occurrence could be attributed to colossal human migration to city areas from rural places, urbanization, and industrialization during 2013 to 2017 facilitated by the high stray dog population. In addition, the destructive earthquake happened in 2015. As a result, Nepal suffered massive damage in infrastructures and other basic amenities such as electricity disrupting the vaccine cold chain systems and veterinary services, which might have led the increased outbreaks.

\section{Conclusion}

Based on the findings, animal rabies is present in Nepal throughout the study period, but an increased number of cases were observed in the last 3 years (20142017). The highest rabies cases were found in dogs, followed by cattle, buffalo, goat, sheep, pig, horse, yak and monkey. At a regional level, the eastern developmental zone had the highest occurrence and central zone recorded the lowest event. Accordingly, in agro-ecological category, the rabies incidence was highest in Terai (plain) area, followed by hills and mountainous areas. Similarly, rabies in animals was present throughout all the seasons. Since dogs are the animal species most affected and defined as a source of rabies, mass dog vaccination program along with humane stray dog sterilization programs using one health approach could effectively reduce and control of rabies in Nepal.

\section{Authors' Contributions}

PP and TR: Conceived the idea and drafted the paper. RB: Assisted in data collection and tabulation. HS and AY: Did the statistical analysis. All authors read and approved the final manuscript.

\section{Acknowledgments}

The authors would like to express their sincere gratitude to the Central Veterinary Hospital, Veterinary Epidemiology and Public Health Division, Kathmandu Animal Treatment Centre, Animal Nepal, and Animal Care Clinic, Chabhil. They are also thankful to the Department of Large Animal and Wildlife Clinical Sciences, Faculty of Veterinary Medicine, Kasetsart University, Thailand, for the graduate research funding.

\section{Competing Interests}

The authors declare that they have no competing interests.

\section{Publisher's Note}

Veterinary World (Publisher of International Journal of One Health) remains neutral with regard to jurisdictional claims in published map and institutional affiliation.

\section{References}

1. Kaplin, C., Turner, G.S. and Warrell, D.A. (1986) Rabies: The Facts. $2^{\text {nd }}$ ed. Oxford University Press, Oxford. p1-126.

2. Singh, R., Singh, K.P., Cherian, S., Saminathan, M., Kappor, S., Reddy, G.B.M., Panda, S. and Dhama, K. (2017) Rabies epidemiology, pathogenesis, public health concerns and advances in diagnosis and control: A comprehensive review. Vet. Q., 37(1): 212-251.

3. Warrell, D.A. and Warrell, M.J. (1995) Human rabies: A continuing challenge in the tropical world. Schweiz. Med. Wochenschr., 125(18): 879-885.

4. Tao, X.Y., Tang, Q., Li, H., Mo, Z.J., Zhang, H., Wang, D.M., Zhang, Q., Song, M., Velasco-Villa, A., 
Wu, X., Rupprecht, C.E. and Liang, G.D. (2009) Molecular epidemiology of rabies in Southern People's Republic of China. Emerg. Infect. Dis., 15(8): 1192-1198.

5. De Mattos, C.A., De Mattos, C.C., Smith, J.S., Miller, E.T., Papo, S., Utrera, A. and Osburn, B.I. (1996) Genetic characterization of rabies field isolates from Venezuela. J. Clin. Microbiol., 34(6): 1553-1558.

6. Pantha, S., Subedi, D., Poudel, U., Subedi, S., Kaphle, K. and Dhakal, S. (2020) Review of rabies in Nepal. One Health, 10: 100155 .

7. Joshi, D.D. and Heron, B.R. (2000) Epidemiology of Rabies and Echinococcosis in Nepal. Proceedings of the $9^{\text {th }}$ International Symposium on Veterinary Epidemiology and Economics. p638.

8. Gongal, G. and Wright, A.E. (2011) Human rabies in the WHO Southeast Asia Region: Forward steps for elimination. Adv. Prev. Med., 2011: 383870

9. Kuensel. (2010) Six Outbreaks in Three Months. Available from: http://www.kuenselonline.com/2010/modmodules. php? name $=$ News \&file $=$ article $\&$ sid $=15101$ Retrieved on 06-07-2019.

10. Pant, G.R. and Bhatta, D.R. (2012) Molecular characterization of rabies virus of Nepal. J. Inst. Med., 33(2): 5.

11. Yamagata, J., Ahmed, K., Khawplod, P., Mannen, K., Xuyen, D.K., Loi, H.H., Dung, N.V. and Nishizono, A. (2007) Molecular epidemiology of rabies in Vietnam. Microbiol. Immunol., 51(9): 833-840.

12. El-Neweshy, M., Mayashi, N.A., Mamari, W.A., Rashdi, Z.A. and Mawly J.H.A. (2020) Animal rabies situation in Sultanate of Oman (2017-2019). Trop. Anim. Health Prod., 52(6): 3069-3076.

13. Tenzin, T., Dhand, N.K. and Ward, M.P. (2011) Patterns of rabies occurrence in Bhutan between 1996 and 2009. Zoonoses Public Health, 58(7): 463-471.

14. Santos, B.L., Bruhn, F.R.P., Coelho, A.C.B., EstimaSilva, P., Echenique, J.V., Sallis, S.V. and Schild, A.L. (2019) Epidemiological study of rabies in cattle in Southern Brazil: Spatial and temporal distribution from 2008 to 2017. Pesq. Vet. Bras., 39(7): 460-468.

15. Feng, Y., Wang, Y., Xu, W., Tu, Z., Liu, T., Huo, M., Liu, Y., Gong, W., Zeng, Z., Wang, W., Wei, Y. and Tu, C. (2020) Animal rabies surveillance, China, 2007-2018. Emerg. Infect. Dis., 26(12): 2825-2834.

16. Hikufe, E.H., Freuling, C.M., Athingo, R., Shilongo, A., Ndevaetela, E.E., Helao, M., Shiindi, M., Hassel, R. Bishi, A., Khaiseb, S., Kabajani, J., van der Westhuizen, J., Torres, G., Britton, A., Letshwenyo, M., Schawabenbauer, K., Mettenleiter, T.C., Denzin, N., Amler, S., Conraths, F.J., Müller, T. and Makeke, A. (2019) Ecology and epidemiology of rabies in humans, domestic animals and wildlife in Namibia, 2011-2017. PLoS. Negl. Trop. Dis., 13(4): e0007355.

17. Ezeokoli, C.D. and Umoh, J.U. (1987) Epidemiology of rabies in northern Nigeria. Trans. R. Soc. Trop. Med. Hyg., 81(2): 268-272.

18. Kalthoum, S., Guesmi, K., Gharbi, R., Baccar, M.N., Seghaier, C., Zrelli, M. and Bahloul, C. (2021) Temporal and spatial distributions of animal and human rabies cases during 2012 and 2018, in Tunisia. Vet. Med. Sci., 7(3): 686-696.
19. Tiwari, H.K., Robertson, I.D., O'Dea, M. and Vanak, A.T. (2019) Demographic characteristics of free-roaming dogs (FRD) in rural and urban India following a photographic sight-resight survey. Sci. Rep., 9(1): 16562.

20. Courtin, F., Carpenter, T.E., Paskin, R.D. and Chomel, B.B. (2000) Temporal patterns of domestic and wildlife rabies in central Namibia stock-ranching area, 1986-1996. Prev. Vet. Med., 43(1): 13-28.

21. Mtai-Malamsha, N., Sallu, R., Mahiti, G.R., Mohamed, H., OleNeselle, M., Rubegwa, B., Swai, E.S., Makungu, S., Otieno, E.G., Lupindu, A.M., Komba, E., Mdegela, R., Assenga, J.A., Bernard, J., Marandu, W., Warioba, J., Makondo, Z., Chang'a, J., Mramba, f., Nonga, H., Killewo, J., Kafeero, F., Makonnen, Y.J., Rivas, A.L. and Fasina, F.O. (2019) Ecologial and epidemiological findings associated with zoonotic rabies outbreaks and control in Moshi, Tanzania, 2017-2018. Int. J. Environ. Res. Public Health, 16(16): 2816.

22. Wheeler, D.C. and Waller, L.A. (2008) Mountains, valleys, and rivers: The transmission of raccoon rabies over a heterogeneous landscape. J. Agric. Biol. Environ. Stat., 13(4): 388-406.

23. Mitmoonpitak, C., Tepsumethanon, V. and Wilde, H. (1998) Rabies in Thailand. Epidemiol. Infect., 120(2): 165-169.

24. Panichabhongse, P. (2001) The Epidemiology of Rabies in Thailand. Master Thesis. Massey University, New Zealand.

25. Baker, L., Matthiopoulos, J., Müller, T., Freuling, C. and Hampson, K. (2019) Optimizing spatial and seasonal deployment of vaccination campaigns to eliminate wildlife rabies. Phil. Trans. R. Soc. B Biol Sci., 374(1776): 20180280 .

26. Abedi, M., Doosti-Irani, A., Jahanbakhsh, F. and Sahebkar, A. (2019) Epidemiology of animal bite in Iran during a 20-year period (993-2013): A meta-analysis. Trop. Med. Health, 47: 55.

27. Yahiaoui, F., Kardjadj, M., Laidoudi, Y., Medkour, H. and Ben-Mahdi, M.H. (2018) The epidemiology of dog rabies in Algeria: Retrospective national study of dog rabies cases, determination of vaccination coverage and immune response evaluation of three commercial used vaccines. Prev. Vet. Med., 158: 65-70.

28. Bouslama, Z., Belkhiria, J.A., Turki, I. and Kharmachi, H. (2020) Spatio-temporal evolution of canine rabies in Tunisia, 2011-2016. Prev. Vet. Med., 185: 105195

29. Grover, M., Bessell, P.R., Canan, A., Polak, P., Sebeta, C.T., Reininghaus, B. and Knobel, D.L. (2018) Spatiotemporal epidemiology of rabies at an interface between domestic dogs and wild in South Africa. Sci. Rep., 8(1): 10864.

30. Guo, D., Yin, W., Yu, H., Thill, J.C., Yang, W., Chem, F. and Wang, D. (2018) The role of socioeconomic and climatic factors in the spatio-temporal variation of human rabies in China. BMC Infect. Dis., 18(1): 256.

31. LeRoux, K., Stewart, D., Perrett, K.D., Nel, L.H., Kessels, J.A. and Abela-Ridder, B. (2018) Rabies control in KwaZulu-Natal, South Africa. Bull. World Health Organ., 96(5): 360-365.

32. Bárcenas-Reyes, I., Nieves-Martínez, D.P., CaudorGil, J.Q., Loza-Rubio, E., González-Ruiz, S., CantóAlarcón, G.J. and Millián-Suazo, F. (2019) Spatiotemporal analysis of rabies in cattle in central Mexico. Geospat. Health, 14(2): 805. 